\title{
Immunohistochemical Analysis of Neuroendocrine (NE) Differentiation in Testicular Germ Cell Tumors (GCTs): Use of Confocal Laser Scanning Microscopy (CLSM) to Demonstrate Direct NE Differentiation from GCTs
}

\author{
Nobue Kumaki ${ }^{1}$, Shinobu Umemura ${ }^{1}$, Hiroshi Kajiwara ${ }^{1}$, Johbu Itoh ${ }^{2}$, Yoshiko Itoh ${ }^{2}$ \\ and R. Yoshiyuki Osamura ${ }^{1}$
}

${ }^{1}$ Department of Pathology, Tokai University School of Medicine, Shimokasuya 143, Isehara, Kanagawa 259-1193, Japan and

${ }^{2}$ Teaching and Research Support Center, Tokai University School of Medicine, Shimokasuya 143, Isehara, Kanagawa 259-1193, Japan

Received November 1, 2007; accepted November 6, 2007; published online December 15, 2007

\begin{abstract}
Neuroendocrine (NE) differentiation is infrequent in testicular tumors and its histogenesis is not well understood. The present study is aimed at elucidating the pathway of neuroendocrine differentiation in germ cell tumors (GCTs) of the testis. In the analysis of 46 germ cell tumor components from 23 testicular tumors, we focused on GCTs with neuroendocrine differentiation, 7 teratoma, 1 embryonal carcinoma and 1 neuroendocrine carcinoma by immunohistochemical study and confocal laser scanning microscopy (CLSM) analysis. NE marker positive cells were noted in the tumor with collision of teratoma and embryonal carcinoma (E\&T tumor), in the immature columnar cells of transitional form of embryonal carcinoma to teratoma (E-T cells) and neuroendocrine carcinoma cells, in addition to the well known mature intestinal mucosa in teratoma. Double staining for a NE marker (CGA) and a germ cell marker (PLAP) demonstrated the localization of both proteins in the same E-T cells confirmed by CLSM. Another finding, indicating the intimate relation between embryonal carcinoma and neuroendcrine differentiation, is that neuroendocrine carcinoma expressed a marker of embryonal carcinoma, CD30. The present results indicated that the NE cells might be differentiated from embryonal carcinoma, a view that has not been proposed before, but that is made in the present study using CLSM.
\end{abstract}

Key words: confocal laser scanning microscopy (CLSM), embryonal carcinoma, germ cell tumor, neuroendocrine cell, testis

\section{Introduction}

It is well known that neuroendocrine tumors (NETs) which produce peptide hormones are equipped with secretory granules (SGs). NETs are derived from endocrine organs such as the anterior lobe of the pituitary, adrenal medulla and pancreatic islets of Langerhans, or scattered endocrine (dispersed neuroendocrine: DNE) cells such as the NE cells originating in the respiratory, gastrointestinal and urinary tracts, as well as the skin [23]. NETs can also be derived from non-endocrine organs such as kidney and liver.

Correspondence to: Nobue Kumaki, Department of Pathology, Tokai University School of Medicine, Shimokasuya 143, Isehara, Kanagawa 259-1193, Japan. E-mail: atrix@is.icc.u-tokai.ac.jp
NETs can occur in the gonads, such as carcinoid tumors of the testis or ovary, but are extremely rare [16]. Even when occurring in the gonads, they often coexist with mature form of germ cell tumor, i.e. teratoma $[1,15,26]$. In the testicular germ cell tumors, in contrast to the ovarian ones, the teratomatous components are often mixed with other types of germ cell tumors [25]. Although there have been a few reports regarding the histogenesis of neuroendocrine tumors in the gonads [20], the detailed mechanisms of differentiation of NETs have yet to be fully elucidated.

Because of their multipotentiality for histological differentiation, germ cell tumors possess a variety of possible histogenetic patterns and are classified into several types based on their histopathological findings. Immunohistochemical examination is another helpful tool to visualize the 
specific molecules in each cell. Placental alkaline phosphatase (PLAP), for example, is a good marker for embryonal carcinoma, and CD30, another recently proposed marker for embryonal carcinoma, is already well known as a marker for Ki-1 lymphoma [14]. There is also a panel of markers for neuroendocrine differentiated cells. The present study is aimed at elucidating the possible origins of NE cells in testicular germ cell tumors using immunohistochemistry combined with confocal laser scanning microscopy (CLSM).

\section{Materials and Methods}

\section{Cases and histopathology}

We investigated 23 testicular tumors including series of the 20 tumors submitted as described in the previous studies $[10,11]$. All tumors were surgically excised at Tokai University Hospital from patients whose ages ranged between 11 months and 53 years (median age, 28.4 years). Nine tumors were obtained from the right testis and 13 from the left (in one case, the testis of origin was unknown). Histological diagnosis was performed according to the General Rules for Clinical and Pathological Studies on Testicular Tumors [22] and WHO classification [2].

Sixteen of the 23 testicular tumors contained more than two histological components, for a total of 46 histopathological components, i.e. 19 embryonal carcinomas, 8 seminomas, 8 yolk sac tumors, 10 teratomas were studied by the following immunohistochemical methods. One neuroendocrine carcinoma was also examined (Table 1).

\section{Immunohistochemistry}

Resected materials were fixed in $10 \%$ formalin and embedded in paraffin. Immunohistochemical examination was performed by the polymer enhancing method (Envision, DAKO). In brief, after deparaffinization, endogenous peroxidase was blocked in $0.3 \% \mathrm{H}_{2} \mathrm{O}_{2}$-methanol solution. Methods of antigen retrieval and the sources of antibodies are summarized in Table 2. The NE markers studied included chromogranin A (CGA), synaptophysin (SYN), neuron specific enolase (NSE), and neural cell adhesion molecule (NCAM, CD56). Placental alkaline phosphatase (PLAP) was used as a marker for embryonal carcinoma and seminoma. After the reaction with peroxidase-labeled poly-
Table 1. Histopathology of the germ cell tumors

\begin{tabular}{lr}
\hline Embryonal carcinoma & 19 \\
Teratoma & 10 \\
Seminoma & 8 \\
Yolk sac tumor & 8 \\
Neuroendocrine carcinoma & 1 \\
\hline
\end{tabular}

mer (Envision, Dako), and the immunoreactions were visualized with DAB (diaminobenzidine). In some cases, CD30 was also examined by automatic system (Ventana XT System Discovery) as a marker of embryonal carcinoma.

\section{Double staining by bright field visualization}

We performed double staining for CGA and PLAP in serial sections from 3 cases, in which CGA or SYN was localized, and from one case of NE carcinomas. Double staining is a useful technique for detecting multiple tissue antigens in the same cells if the control studies are properly performed [12]. DAB was used for visualization of the first immunohistochemical staining for CGA. For immunostaining for PLAP, a second antigen, the immunoreactions were visualized using Fast Blue BB. In the process of double staining for CGA and PLAP, both antibodies were generated in mice, and the primary and secondary antibodies for the first staining were removed by washing in glycine $\mathrm{HCl}$ buffer for 1-2 hr with stirring, before the immunoreaction of the second staining.

\section{CLSM analysis}

In order to elucidate whether PLAP and CGA were localized in the same cell, CLSM (LSM-510 META; Carl Zeiss, Jena, Germany) in reflection and fluorescence mode was employed on the selected immunoreacted cells on the paraffin sections. The CLSM system included a 543-nm helium-neon laser (for fast blue fluorescence and reflection of DAB). Optical fluorescence signals of alkaline phosphatase labeled with fast blue were observed using a dichroic beam splitter (NT 80/20/543; Carl Zeiss) and emission filter (LP570; Carl Zeiss) [5]. Optical reflectance signals from CGA-positive cells labeled with DAB were observed using a dichroic beam splitter (NT 80/20/543; Carl Zeiss) without an emission filter. Double- or triple-labeled data sets

Table 2. Antibodies used in this study

\begin{tabular}{|c|c|c|c|c|}
\hline Antibody & dilution & Clone & Retrieval & Company \\
\hline Chromogranin A & $1: 1$ (prediluted) & LK2H10 & - & IMMUNO TECH \\
\hline Synaptophysin & $1: 50$ & Polyclonal & $+* 1$ & DAKO \\
\hline NCAM & $1: 30$ & $1 \mathrm{~B} 6$ & $+* 2$ & NOVO CASTRA \\
\hline PLAP & $1: 100$ & $8 \mathrm{~A} 9$ & - & DAKO \\
\hline CD 30 & $1: 30$ & Ber-H2 & $+* 2$ & DAKO \\
\hline
\end{tabular}

NSE, neuron specific enolase; NCAM, Neural cell adhesion molecule; PLAP, Placental alkaline phosphatase.

Antigen retrieval $* 1: 0.1 \%$ Trypsin solution $(0.05 \mathrm{M}$ Tris- $\mathrm{HCl}$ buffer $), 37^{\circ} \mathrm{C}, 30 \mathrm{~min}, * 2$ : Autoclave in $\mathrm{pH} 6.0$ citrate buffer solution, $121^{\circ} \mathrm{C}, 2$ atm, $15 \mathrm{~min}$. 
(including transmittance images) of images obtained by CFLSM were digitized and subjected to image analysis using LSM software version 3.2 SP2 (Carl Zeiss). Optical imaging for 2D reconstruction of PLAP- and CGA-secreting endocrine cells was performed with a $\mathrm{C}$-apochromat ( $\times 63$, water immersion, NA 1.25; Carl Zeiss) objective lens. The image resolution was $512 \times 512$ pixels (12 bits, 4096 gray levels).

\section{Immunoelectron microscopy for CGA positive cells in neuroendocrine carcinoma}

Immunoelectron microscopic examination was performed by the pre-embedding method using paraffin sections. After immunohistochemical reaction was completed, the reacted paraffin sections were re-fixed with $0.5-1 \%$ glutaraldehyde. Visualization with DAB was performed, followed by osmification and dehydration with ethanol, after which sections were then embedded in epoxy resin. The resin was polymerized at $60^{\circ} \mathrm{C}$ for 2 days. Ultrathin sections were observed under the electron microscope (JEOL 1200EX, JEOL Ltd., Tokyo, Japan).

\section{Results}

\section{Characteristics of germ cell tumor expressing NE markers}

Germ cell tumors (GCTs) often show more than two histological elements; therefore, immunohistochemical staining was performed for each histological component. The results of single immunohistochemical staining are summarized in Table 3. Expression of NE markers was identified in most of teratomas which included intestinal or respiratory tract. Teratomatous components usually contained mature components of skin with or without adnexa, bronchus, gastrointestinal tract, bone, cartilage, muscle and neural tissue. Columnar cells in mature intestinal tissue contained basally situated nucleus and cilia, and goblet cells were also seen (Fig. 1A). A few cells in a case of embryonal carcinoma and a case of yolk sac tumor were also positive for CGA. Many tumor cells of the neuroendocrine carcinoma (NEC) were labeled for NE markers including CGA, SYN, NSE and NCAM.

To analyze the relation between NE character and germ cell tumors more precisely, we focused on the following three resected tumorous elements.

(1) The first element was the collision of teratoma and embryonal carcinoma (Fig. 1B). The columnar cells in glandular structures were observed as admixed with or adjacent to embryonal carcinomas. We called this element "E\&T tumor" (mixture of embryonal carcinoma and teratoma).

(2) For the second element, immature intestinal tubules consisted of columnar cells with less basally oriented nuclei and cilia, and very slight mucus production was observed (Fig. 1C). From these features, these columnar cells were interpreted as less mature intestinal cells. On the other hand, embryonal carcinoma cells sometimes are columnar shaped and contain clear cytoplasm [6]. They are also arranged in papillary structure. Therefore, we designated these tumor cells as transitional "embryo-teratoma cells" (E-T cells).

(3) The third element with striking features was neuroendocrine carcinoma (NEC), which was composed of small markedly atypical cells arranged in solid nests with occasional rosette formation (Fig. 2A). Although no typical features of carcinoid tumors, such as ribbon-like, rosette-like or gyrus-like appearance were observed, immunohistochemical staining showed positive NE markers such as CGA, SYN, NSE and NCAM. Seminoma cells were intimately admixture with NEC cells.

\section{Immunohistochemical staining for germ cell tumors and double staining for PLAP/CD30 and CGA}

Recently CD30 has been proposed as a marker of embryonal carcinoma in addition to PLAP. Seminoma is also positive for PLAP, which can be differentiated from embryonal carcinoma by negativity for CD30. Therefore, immunohistochemical stain for CD30 and double stain for germ cell marker/NE markers were performed in the above three tumorous elements.

Our observations clearly indicated that CLSM showed unique fluorescence for DAB and Fast Blue BB. The former was noticed in yellow and the latter in blue. This was particularly more discernible when two molecules were detected in the same cell. Thus, the double-stained slides were first examined with bright field condition and subsequently by CLSM. The morphology and the localization in the same cell were evaluated with improved quality by this method.

(1) For the "E\&T tumor" element, PLAP and CD30positive cells were noted in the embryonal carcinoma and CGA-positive NE cells were present in the intestinal teratoma. They were not overlapping, but were next to each other (Fig. 1E). This was also clearly discernible by

Table 3. Results of immunohistochemical staining in testicular germ cell tumors (percentage)

\begin{tabular}{llllll}
\hline Histopathology & CGA & SYN & NSE & NCAM & PLAP \\
\hline NE carcinoma & $1 / 1(100)$ & $1 / 1(100)$ & $1 / 1(100)$ & $1 / 1(100)$ & $0 / 1$ \\
Teratoma & $7 / 10(70)$ & $3 / 10(30)$ & $0 / 10$ & $4 / 10(40)$ & $0 / 7$ \\
Embryonal carcinoma & $1 / 19(5)$ & $0 / 19$ & $6 / 19(32)$ & $0 / 11$ & $16 / 16(100)$ \\
Seminoma & $0 / 8$ & $0 / 8$ & $0 / 8$ & $0 / 5$ & $6 / 6(100)$ \\
Yolk sac tumor & $1 / 8(13)$ & $0 / 8$ & $0 / 8$ & $2 / 7(29)$ & $4 / 8(50)$ \\
\hline
\end{tabular}

NE carcinoma, neuroendocrine carcinoma; CGA, chromogranin A; SYN, synaptophysin; NSE, neuron specific enolase; PLAP, Placental alkaline phosphatase; NCAM, neural cell adhesion molecule. 
E\&T
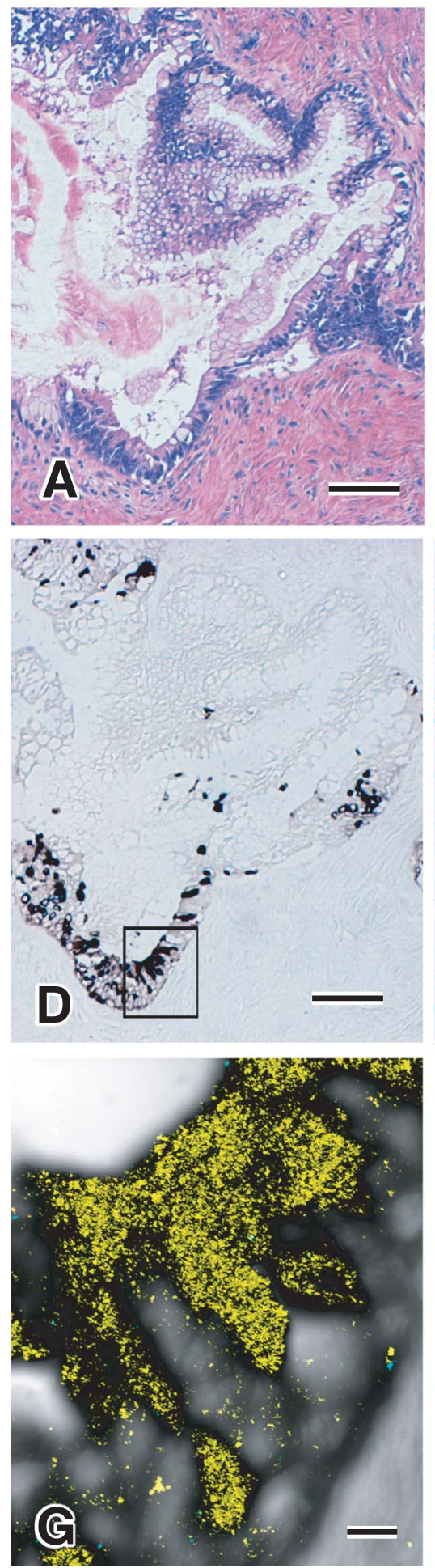
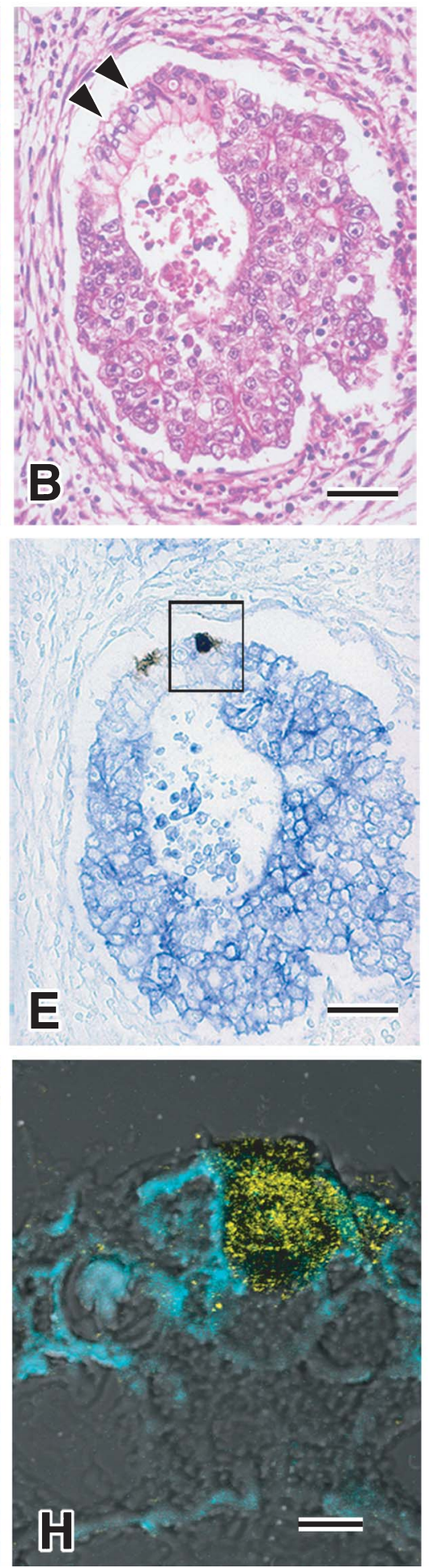

E-T
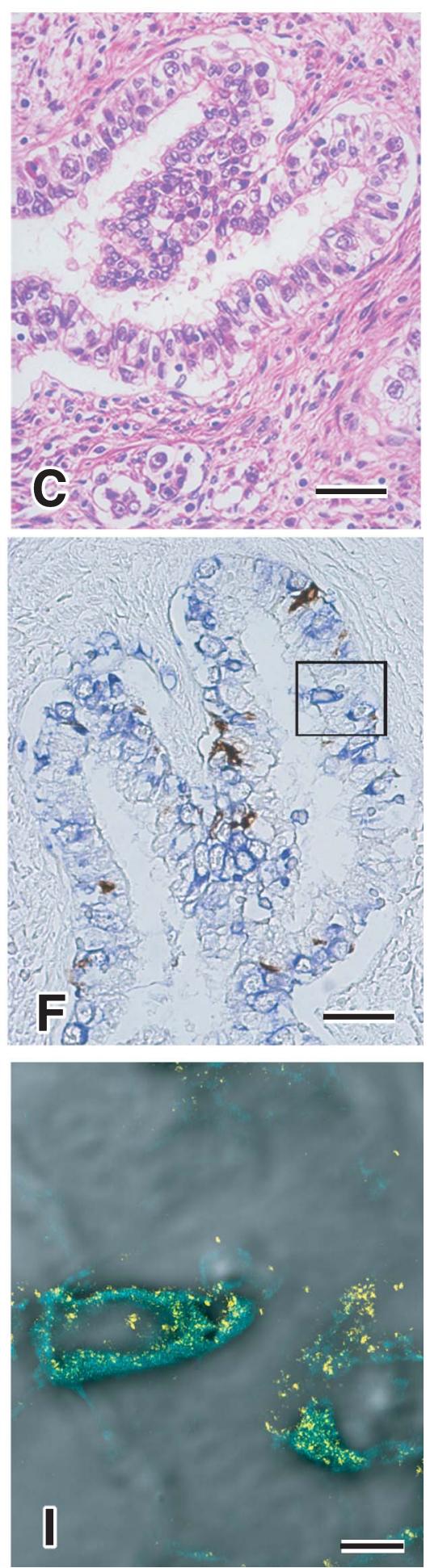

Fig. 1. Neuroendocrine cells in germ cell tumors. Among columnar cells in mature intestinal mucosa of teratoma (A), there are neuroendocrine cells labeled by CGA $(\mathbf{D}, \mathbf{G})$. In the area consisting of intestinal columnar cells of teratoma (black arrowhead) and embryonal carcinoma cells (B), CGA positive neuroendocrine cells and PLAP positive embryonal carcinoma cells are closely localized but not localized in the same cells $(\mathbf{E}, \mathbf{H})$. Immature columnar epithelial cells $(\mathbf{C})$ demonstrate a few immature columnar cells are positive for both CGA and PLAP (F, I). Bars $=100 \mu \mathrm{m}(\mathbf{A}-\mathbf{E}), 50 \mu \mathrm{m}(\mathbf{F}), 5 \mu \mathrm{m}(\mathbf{G}-\mathbf{I})$. A-C: H\&E stain, D-F: double immunohistochemical stain for CGA (brown) and PLAP (blue), and G-I: merged images of CLMS for CGA (yellow) and PLAP (cyanogen). 


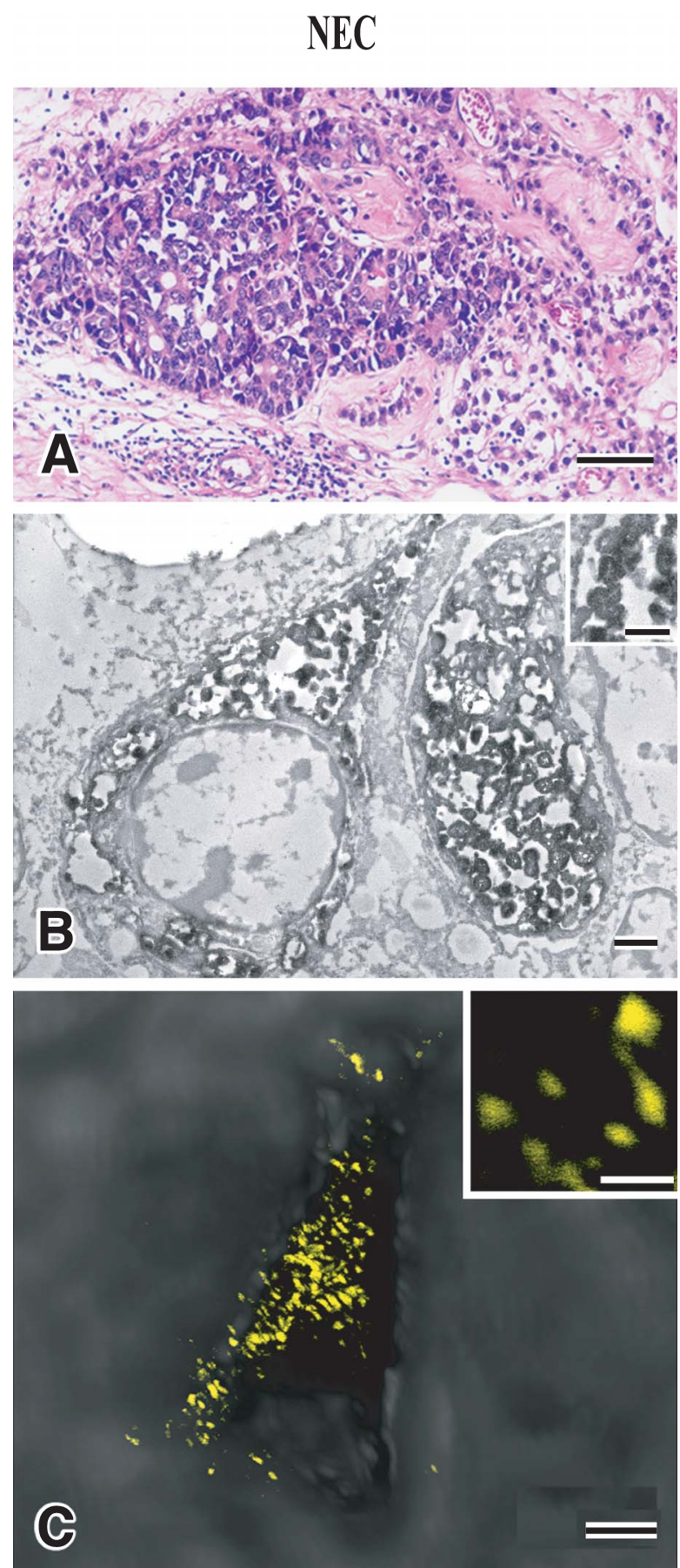

Fig. 2. Histological, immunohistochemical and immunoelectron microscopic features of neuroendocrine carcinoma (NEC). Tumor consists of sheets of small and atypical epithelial cells which are adjacent to seminoma cells (A). Immunoelectron microscopical analysis shows that NEC cells have granules positively labeled by CGA (B). The sizes of granules measured by electronmicroscopy and by CLSM are approximately equal to $200-300 \mathrm{~nm}$. Bars $=100$ $\mu \mathrm{m}(\mathbf{A}), 1.0 \mu \mathrm{m}$ (B), $0.5 \mu \mathrm{m}$ (B, inset), $2.0 \mu \mathrm{m}(\mathbf{C}), 0.2 \mu \mathrm{m}(\mathbf{C}$, inset). A: H\&E stain, B: immunohistochemical and immunoelectron microscopy, C: CLSM for CGA (yellow).
CSLM (Fig. 1H).

(2) For the "E-T cell" element, membranous expression of PLAP was detected in many E-T cells and expression of CGA was frequently observed in E-T cells. However, these E-T cells were not labeled by CD30. Bright field double staining for PLAP (blue) and CGA (brown) demonstrated the localization of both proteins in the same "E-T cells" (Figs. 1F, 3A). CLSM showed more clearly the co-localization of PLAP on the cell membrane and CGA in the cytoplasm (Figs. 1I and 3D). In this case, the "E-T cells" revealed tubular structures lined by clear and irregular columnar cells which were histopathologically interpreted as a transitional form exhibiting the features of both intestinal cells (teratomatous) and embryonal carcinoma, with PLAP and CGA being localized in the same cells (Fig. 3).

(3) The third group of tumor also showed the separate groups of tumor cells, i.e. seminoma and NEC. Expression of PLAP and CD30 was noted in seminoma, but NE markers were negative. NEC cells were positive not only for NE markers but also for CD30 (Fig. 4A). Even though SYN positive tumor cells were focally observed in NEC (Fig. 4C), CGA positive NEC cells were very small in number (Fig. 4B). Many NEC cells were positive for CD30 and cytoplasmic localization of CD30 was clearly detected by CLSM (Fig. 4D). CD30 expression was usually noted at the cell membrane, as is demonstrated in embryonal carcinoma cells (Fig. 4E). CLSM examination obviously revealed differentiation of signal localization of CD30 in each tumor. No tumor cells with expressions of both CD30 and NE markers were observed.

\section{Immunoelectron microscopy}

Immunoelectron microscopy pre-embedding method using formalin-fixed, paraffin-embedded materials after immunoreaction with DAB colorization revealed the localization of CGA in granular structures of up to $300 \mathrm{~nm}$ in diameter, which were interpreted as secretory granules (SG) (Fig. 2B). Granular structures by CLSM for CGA positive cells in NEC cells showed similar granular structures suggesting its localization in SG (Fig. 2C).

\section{Discussion}

From our studies, it was clearly demonstrated that the neuroendocrine (NE) cells appear in various types of germ cell tumors (GCTs) of the testis including teratomas (especially in the intestinal epithelial cells), embryonal carcinomas and yolk sac tumors. In addition, neuroendocrine carcinoma (NEC) was concomitantly present with seminoma in the same tumor but separately. Histogenesis of NE cells has been postulated to take place along various pathways, (1) epithelial origin, (2) neural origin and (3) dedifferentiated tumor cells. To determine how NE differentiation appears in the testicular GCTs, we conducted an immunohistochemical examination which showed that there were three different situations: (1) CGA-positive cells appear in mature teratomatous intestinal glands mixed in embryonal carci- 

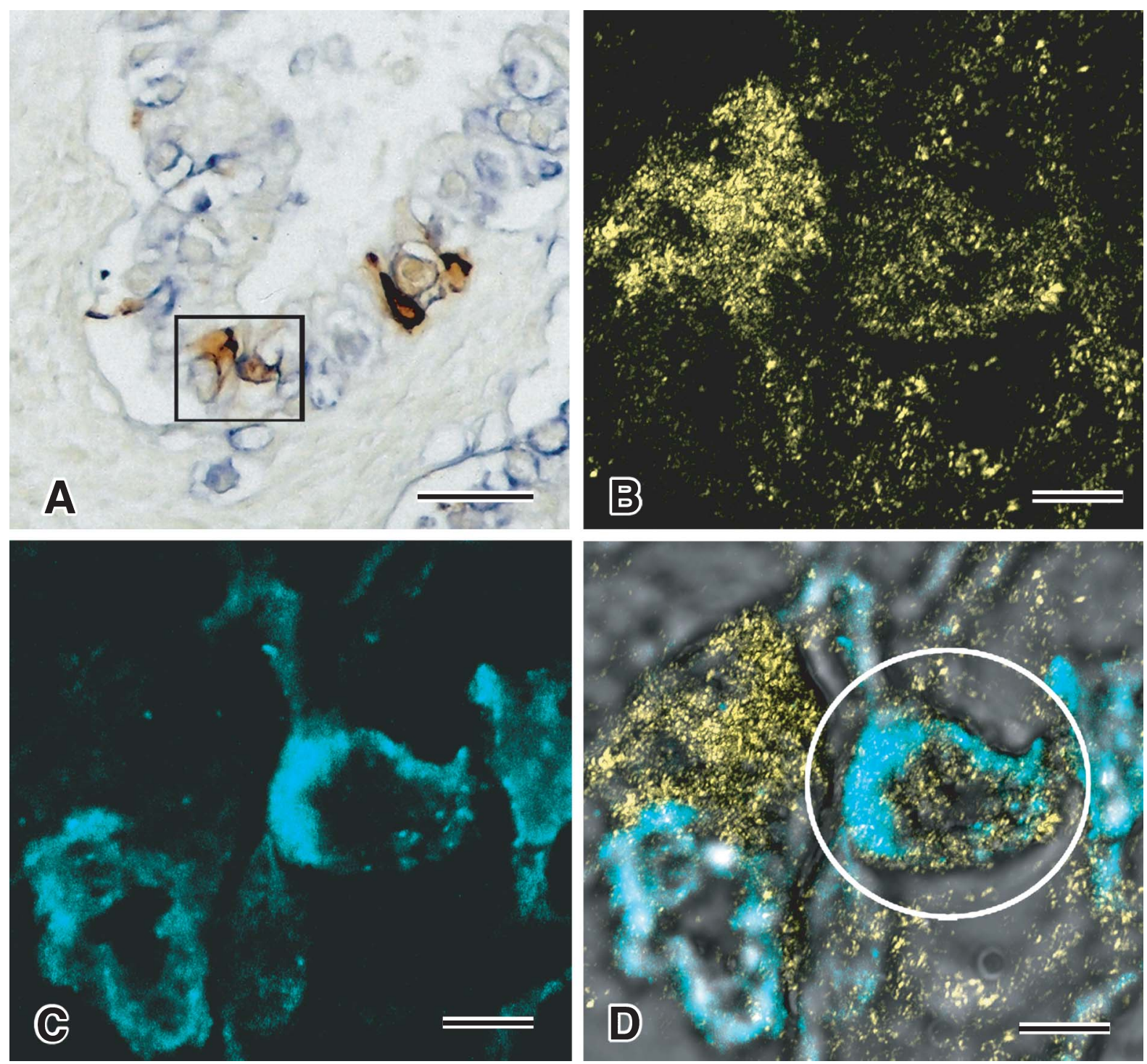

Fig. 3. Localization of CGA and PALP in the same E-T cells. In double immunohistochemical staining for CGA (brown) and PLAP (blue) (A),

CGA and PALP are observed in the same cell. Analysis by CLSM demonstrates the detected cells are positively labeled by both CGA (yellow) (B) and PLAP (cyanogen) (C), and the merged image shows both signals in the same cell (D). Bars=50 $\mu \mathrm{m}(\mathbf{A}), 5 \mu \mathrm{m}(\mathbf{B}-\mathbf{D})$.

noma "E\&T tumor", (2) CGA appears in tubular structures (E-T cells) which exhibit the features in transition from embryonal carcinoma to teratomatous intestinal glands, (3) NEC separates from seminoma. By CLSM on immunohistochemical double staining, the three categories noted above were clearly observed. In particular, this novel method specifically indicated the localization of CGA and PLAP in the same E-T cells. These findings support the hypothesis that the NE cells may be differentiated from embryonal carcinoma during the process of columnar (intestinal) morphogenesis (Fig. 5).

It is well known that CGA is a major component in the secretory granules and has been used as a major NE marker in NE cells and neuroendocrine tumors (NETs). Recently, it has been reported that CGA gene transfection induced the formation of secretory granules which are the morphological feature of NE cells [4]. The molecular mechanisms for the appearance of CGA in the embryonal carcinoma remain to be further investigated.

Primary NET by WHO classification included (1) well differentiated endocrine tumor (WDET) "carcinoid", (2) well differentiated endocrine carcinoma (WDEC) and (3) poorly differentiated endocrine carcinoma (PDEC). The "carcinoid" occurs only rarely in the testis, but is fairly common in the ovary. The majority of primary ovarian "carcinoid" tumors coexist with teratomas [17], but testicular "carcinoid" tumors are not always associated with teratomas $[1,13,16,20,26]$. Two possible explanations have been proposed for the origins of testicular "carcinoid tumors" [20]: (1) carcinoid tumors originate from the NE cells present in the intestinal or bronchial component of teratomas that consist of various types mature and immature 

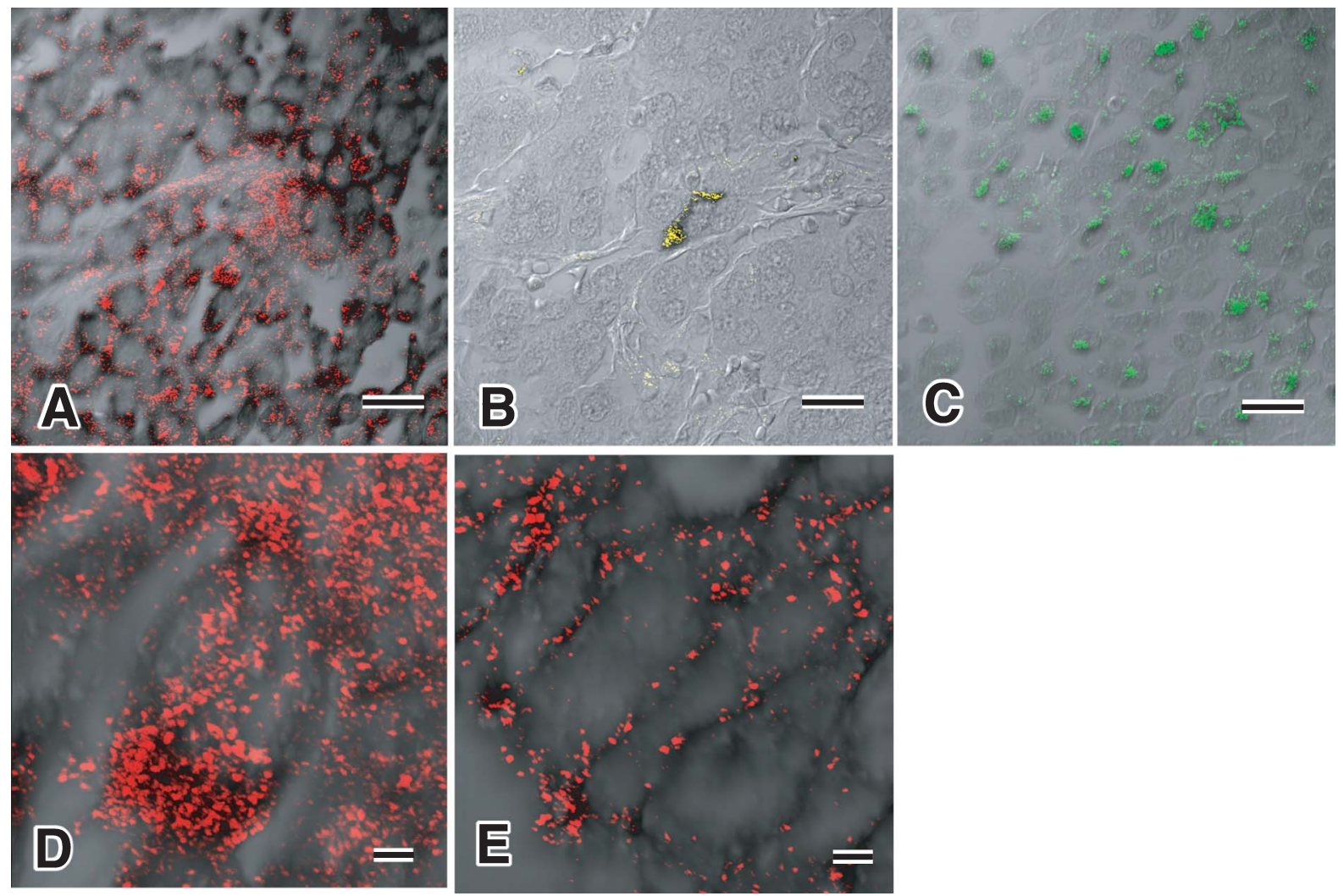

Fig. 4. Expression of CD30, a marker of embryonal carcinoma, in neuroendocrine carcinoma. CLSM shows that neuroendocrine carcinoma demonstrates expression of CD30 (A, D), CGA (B) and synaptophysin $(\mathbf{C})$. Intracytoplasmic localization of CD30 in embryonal carcinoma is in the cytoplasm(D), in contrast to typical expression pattern at cellular membrane in embryonal carcinoma $(\mathbf{E})$. Bars=20 $\mu \mathrm{m}(\mathbf{A}-\mathbf{C}), 2.0 \mu \mathrm{m}(\mathbf{D}, \mathbf{E})$.

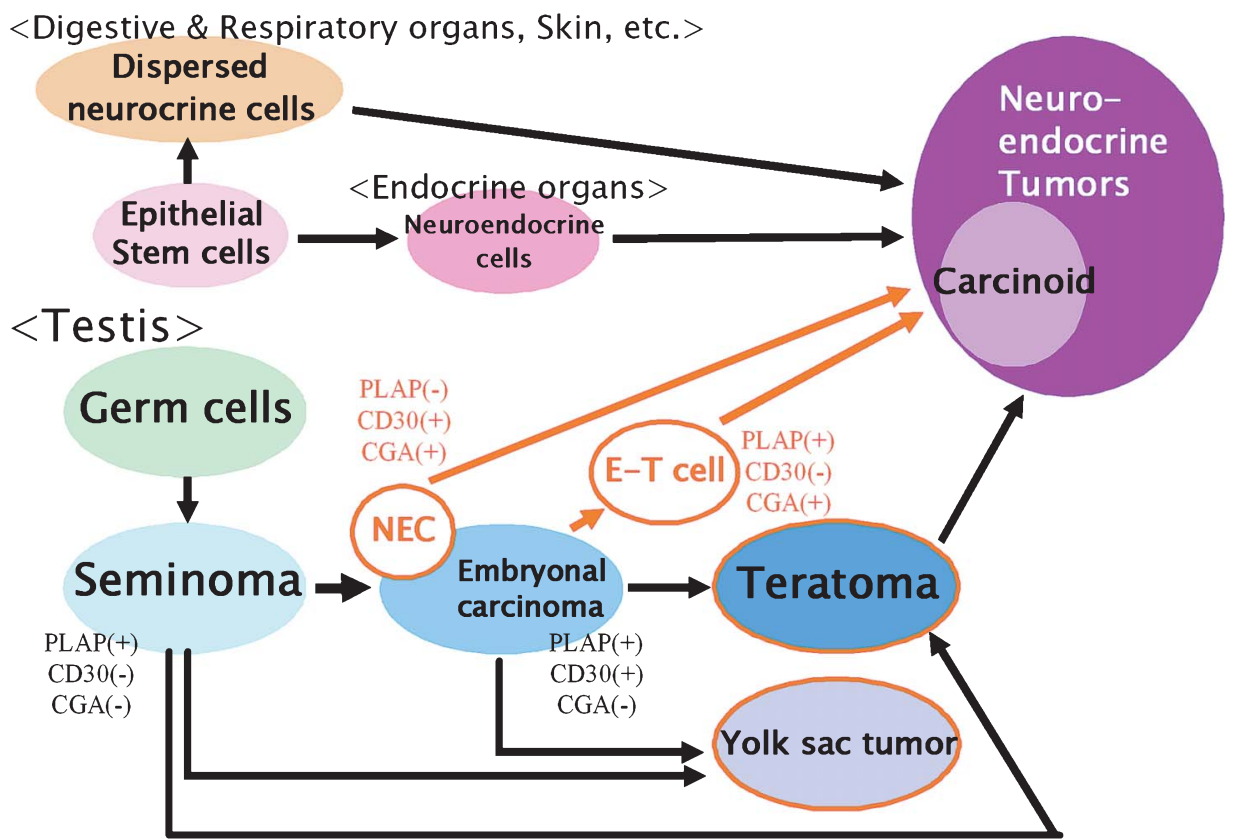

Fig. 5. A proposed hypothesis for histogenesis of neuroendocrine tumor in testis. The two cases presented in this study may indicate alterative pathways from embryonal carcinoma other than through mature teratoma (Red circled tumor; CGA positive tumor in this study). 
tissue; and (2) carcinoid tumors originate from NE cells present in the non-neoplastic gonadal elements. Although there is no evidence of NE cells in the gonad, pluripotent cells similar to ES cells were recently found in mouse testis [8].

Primordial germ cells appear in the yolk sac endoderm and migrate to the gonadal ridge in early embryonic life [21, 24]. Because germ cell tumors are thought to be derived from these primordial germ cells before they become gametes, various mature or immature histological features are observed which mimic the process of normal development. At present, embryonal carcinoma is suggested to occur from seminoma because seminoma cells are thought to have pluripotency, and nonseminomatous germ cell tumors (NSGCTs) are assumed to occur from embryonal carcinoma or seminoma $[3,9,19]$.

The third tumor element, NEC, in our study was interpreted as PDEC and was found to co-exist with seminoma; these two tumors were located next to each other and were admixed at the transition. This tumor was not only positive for NE markers, but also for one of the markers for embryonal carcinoma, CD30, even though PLAP was negative. The results of immunohistochemical staining and co-existence of NEC and seminoma showed that this third tumor element has a potential for differentiation into both embryonal carcinoma and NETs (Fig. 5). Moreover, the fact that less mature germ cell tumors than teratoma have an NE characteristic may support the hypothesis that NEC could be derived from GCTs.

One of the major pluripotent cells is the embryonal stem (ES) cell in human and other species. ES cells cultured under special conditions or with various materials can differentiate into myocardial cells, hepatic cells, hematopoietic cells and even into endocrine cells. Differentiated endocrine cells are similar to beta cells of pancreatic islet cells, and can secrete insulin in vitro [18]. However, morphological studies of ES cells have been not extensive. Kanatsu-Shinohara et al. report that testicular cells of newborn mouse can continue to proliferate under the same conditions of ES cell culture method [7]. These cultured cells reveal very similar characters to ES cells, and their germline potential is preserved. These findings suggest that multipotent stem cells are present in the testis and could differentiate into neuroendocrine cells in the gonad. Our findings support the spontaneous differentiation of NE cells from ES cells in the culture condition.

In conclusion, NE differentiation was observed in three categories: (1) "E\&T tumor", (2) "E-T cell”, and (3) NEC. Our findings suggest that germ cell tumor acquires the NE characteristic during the immature phase of teratomatous differentiation ("E-T cell"). NEC in our case was of particular interest because of the presence of NEC and seminoma in the same tumor, both of which were decorated by CD30 suggesting that NE differentiate from less differentiated seminoma.

These findings may shed new light on cancer pathobiology by clarifying the pathway of NE differentiation in various cancers including GCTs. Moreover, it should be emphasized that we can more precisely observe the tumor cell structure by use of CLSM with bright immunohistochemical localization of dyes in the same cell, DAB and Fast Blue $\mathrm{BB}$, and that CLSM is particularly useful to apply to specimens of resected archival human tumors.

\section{Acknowledgments}

We wish to thank Akihiko Serizawa (Division of Pathology, Tokai University Hospital) for technical support.

\section{References}

1. Czopek, J. and Frasik, W. (1996) Carcinoid tumor as a part of mature teratoma of the testis. Pol. J. Pathol. 47; 91-93.

2. Eble, J. N., Sauter, G., Epstein, J. I. and Sesterhenn, I. A. (ed.) (2004) WHO Classification of Tumors. Tumors of the Urinary System and Male Genital Organs. IARC Press, Lyon.

3. Hata, J. and Fujimoto, J. (1987) Differentiating capability of human germ cell tumors. Pathol. Clin. Med. 5; 29-37.

4. Inomoto, C., Umemura, S., Egashira, N., Minematsu, T., Takekoshi, S., Itoh, Y., Itoh, J., Taupenot, L., O'Connor, D. T. and Osamura, R. Y. (2007) Granulogenesis in non-neuroendocrine COS-7 cells induced by EGFP-tagged chromogranin A gene transfection: identical and distinct distribution of $\mathrm{CgA}$ and EGFP. J. Histochem. Cytochem. 55; 487-493.

5. Itoh, J., Matsuo, A., Yamamoto, Y., Kawai, K., Serizawa, A., Watanabe, K., Itoh, Y. and Osamura, R. Y. (2001) Confocal laser scanning microscopic imaging of subcellular organelles, mRNA, protein products, and the microvessel environment. Acta Histochem. Cytochem. 34; 285-297.

6. Jacobsen, G. K. and Talerman, A. (1989) Atlas of Germ Cell Tumors. Munksgaard Publishing, Copenhagen.

7. Kanatsu-Shinohara, M., Ogonuki, N., Inoue, K., Miki, H., Ogura, A., Toyokuni, S. and Shinohara, T. (2003) Long-term proliferation in culture and germline transmission of mouse male germline stem cells. Biol. Reprod. 69; 612-616.

8. Kanatsu-Shinohara, M., Inoue, K., Lee, J., Yoshimoto, M., Ogonuki, N., Miki, H., Baba, S., Kato, T., Kazuki, Y., Toyokuni, S., Toyoshima, M., Niwa, O., Oshimura, M., Heike, T., Nakahata, T., Ishino, F., Ogura, A. and Shinohara, T. (2004) Generation of pluripotent stem cells from neonatal mouse testis. Cell 119; 1001-1012.

9. Konishi, N. (2000) Germ cell tumors of testis. Pathol. Clin. Med. $18 ; 1307-1311$.

10. Kumaki, N., Kajiwara, H., Umemura, S., Yasuda, M. and Osamura, R. Y. (2001) Study of the generation of neuroendocrine cells in testicular germ cell tumors. Horumon to Rinsho 49 (supplement); 225-229 (In Japanese).

11. Kumaki, N., Kajiwara, H., Umemura, S., Yasuda, M. and Osamura, R. Y. (2002) Expression of neuroendocrine markers in testicular germ cell tumors of human. Horumon to Rinsho 50 (supple); 246-252 (In Japanese).

12. Nakane, P. K. (1968) Simultaneous localization of multiple tissue antigens using the peroxidase-labeled antibody method. A study on pituitary glands of the rat. J. Histochem. Cytochem. 16; 557560 .

13. Ordonez, G. N., Ayala, G. A., Snelge, N. and Mackay, B. (1982) Immunohistochemical demonstration of multiple neurohormonal polypeptides in a case of pure testicular carcinoid. Am. J. Clin. Pathol. 78; 860-864.

14. Pallesen, G. and Hamilton-Dutoit, S. J. (1988) Ki-1 (CD30) antigen is regularly expressed by tumor cells of embryonal carcinoma. Am. J. Pathol. 133; 446-450. 
15. Reyes, A., Moran, C. A., Suster, S., Michal, M. and Dominguez, H. (2003) Neuroendocrine carcinomas (carcinoid tumor) of the testis. Am. J. Clin. Pathol. 120; 182-187.

16. Richie, J. P. and Steele, G. S. (2007) Neoplasm of the testis. In "Campbell-Walsh Urology 9th ed.", ed. by A. J. Wein, L. R. Kavoussi, A. C. Novick, A. W. Partin and C. A. Peters. Saunders, Philadelphia, PA, pp. 893-935.

17. Robby, S. J., Scully, R. E. and Norris, H. J. (1975) Insular carcinoid primary in the ovary. A clinicopathologic analysis of 48 cases. Cancer 36; 404-418.

18. Santana, A., Ensenat-Waser, R., Arribas, M. I., Reig, J. A. and Roche, E. (2006) Insulin-producing cells derived from stem cells: recent progress and future directions. J. Cell. Mol. Med. 10; 866883.

19. Srigley, J. R., Mackay, B., Toth, P. and Ayala, A. (1988) The ultrastructure and histogenesis of male germ neoplasia with emphasis on seminoma with early carcinomatous feature. Ultrastruc. Pathol. 12; 67-86.

20. Talerman, A., Gratama, S., Miranda, S. and Okagaki, T. (1978) Primary carcinoid tumor of the testis, case report, ultrastructure and review of the literature. Cancer 42; 2696-2706.

21. Teshima, S. and Shimosato, Y. (1987) Human germ cell tumor: its histogenesis and morphogenesis. Pathol. Clin. Med. 5; 10-17.
22. The Japanese Urological Association \& The Japanese Society of Pathology (ed.) (2005) General Rules for Clinical and Pathological Studies on Testicular Tumors, 3rd ed. Kanehara-shuppan Publishing, Tokyo.

23. Tischler, A. S. (1989) The dispersed neuroendocrine cells: the structure, function, regulation and effects of xenobiotics on this system. Toxicol. Pathol. 17; 307-316.

24. Trainer, D. T. (2007) Testis and excretory duct system. In "Histology for Pathologists, 3rd ed.”, ed. by S. E. Mills. Lippincott Williams \& Wilkins, Philadelphia, pp. 943-964.

25. Ulbright, T. M. (2005) Germ cell tumors of the gonads: a selective review emphasizing problems in differential diagnosis, newly appreciated, and controversial issues. Modern Pathol. 18 (supplement); S61-S79.

26. Zavala-Pompa, A., Ro, J. Y., El-Neggar, A., Ordonez, N. G., Amin, M. B., Pierce, P. D. and Ayala, A. G. (1993) Primary carcinoid tumor of testis. Cancer $72 ; 1726-1732$.

This is an open access article distributed under the Creative Commons AttribuThis is an open access article distributed under the Creative Commons Attribu-
tion License, which permits unrestricted use, distribution, and reproduction in any medium, provided the original work is properly cited. 